CARDIOVASCULAR MEDICINE

\title{
Contemporary management of acute coronary syndromes: does the practice match the evidence? The global registry of acute coronary events (GRACE)
}

\author{
K F Carruthers, O H Dabbous, M D Flather, I Starkey, A Jacob, D MacLeod, K A A Fox, on behalf \\ of the GRACE Investigators
}

Heart 2005;91:290-298. doi: 10.1136/hrt.2003.031237

See end of article for authors' affiliations

Correspondence to: Professor Keith A A Fox, Cardiovascular Research Division of Medical and Radiological Sciences, University of Edinburgh, Chancellor's Building, 49 Little France Crescent, Edinburgh EH16 4SB, UK; k.a.a.fox@ed.ac.uk

Accepted 15 April 2004

\begin{abstract}
Objective: To determine to what extent evidence based guidelines are followed in the management of acute coronary syndromes (ACS) in the UK, elsewhere in Europe, and multinationally, and what the outcomes are.

Design: Multinational, prospective, observational registry (GRACE, global registry of acute coronary events) with six months' follow up.

Setting: Patients presenting to a cluster of hospitals. The study was designed to collect data representative of the full spectrum of ACS in specific geographic populations.

Patients: Patients admitted with a working diagnosis of unstable angina or suspected myocardial infarction (MI).

Main outcome measures: Death during hospitalisation and at six months' follow up (adjusted for baseline risks).

Results: In ST elevation MI, reperfusion was applied more often in the UK (71\%) than in Europe (65\%) and multinationally $(59 \%)(p<0.01)$. However, this was almost entirely by lytic treatment, in contrast with elsewhere (primary percutaneous coronary intervention 1\%, 29\%, 16\%, respectively). Statins were applied more frequently in the UK for all classes of patients with ACS ( $p<0.0001)$. In contrast there was lower use of revascularisation procedures in non-ST MI (20\% v $37 \%$ v $28 \%$, respectively) and glycoprotein $\mathrm{llb} / \mathrm{llla}$ antagonists ( $6 \% \vee 25 \% \vee 26 \%$, respectively). In-hospital death rates, adjusted for baseline risk, were not significantly different but six month death rates were higher in the UK for ST elevation MI (7.2\% UK, $4.3 \%$ Europe, $5.3 \%$ multinationally; $\mathrm{p}<0.0001)$ and non-ST elevation $\mathrm{MI}(7.5 \%, 6.2 \%$, and $6.7 \%$, respectively; $\mathrm{p}=0.012$, UK $v$ Europe).

Conclusions: Current management of ACS in the UK more closely follows the recommendations of the National Service Framework than British or European guidelines. Differences in practice may account for the observed higher event rates in the UK after hospital discharge.
\end{abstract}

\begin{abstract}
A cute coronary syndromes (ACS) are a major cause of morbidity and mortality and constitute the largest medical indication for hospitalisation in the UK. ${ }^{1}$ Insights into the pathophysiology of ACS and evidence from trials of pharmacological and interventional (revascularisation) treatment have led to the update of guidelines in the $\mathrm{UK}^{2}{ }^{2}$ in Europe, ${ }^{3}{ }^{4}$ and in the USA. ${ }^{5}$ Previous surveys have indicated that British practice was not consistent with guidelines and in many cases did not match that of other European countries (ENACT (European network for acute coronary treatment), ${ }^{6}$ PRAIS-UK (prospective registry of acute ischemic syndromes in the UK $\left.)^{7}\right)$. However, the extent to which such guidelines have been implemented in contemporary clinical practice in the UK is unknown.

Key elements from the current guidelines of the European Society of Cardiology recommend that patients with ST segment elevation or new left bundle branch block should be reperfused either by primary percutaneous coronary intervention (PCI) performed 90 minutes after the first medical contact or by thrombolysis within 30 minutes of presentation to hospital. ${ }^{3}$ Patients without ST segment elevation should be stratified into high or low risk and both groups should receive aspirin, low molecular weight heparin, clopidogrel, $\beta$ blockers, and nitrates. High risk patients should receive a glycoprotein IIb/IIIa inhibitor and undergo coronary angiography (table 1).
\end{abstract}

The British Cardiac Society guideline for non-ST segment elevation ACS also stratifies patients into high, intermediate, and low risk groups. ${ }^{2}$ They recommend antithrombotic treatment with aspirin, low molecular weight heparin, $\beta$ blockers, and nitrates and that high and intermediate risk patients should receive an intravenous glycoprotein IIb/IIIa inhibitor and be referred for coronary angiography (table 1).

The National Service Framework (NSF) for coronary heart disease is a British government publication that aims to provide quality standards of management for coronary heart disease. ${ }^{8}$ Key recommendations are that patients with acute myocardial infarction (MI) should be treated with aspirin, given a thrombolytic within an hour of the onset of symptoms, and be commenced on both a $\beta$ blocker and an angiotensin converting enzyme (ACE) inhibitor (table 1). Primary PCI is not mentioned as a method of reperfusion for patients with ST elevation MI, but these recommendations were made in 2000.
Abbreviations: $A C E$, angiotensin converting enzyme; $A C S$, acute coronary syndromes; ASPIRE, action on secondary prevention through intervention to reduce events; ENACT, European network for acute coronary treatment; GRACE, global registry of acute coronary events; $\mathrm{MI}$, myocardial infarction; MONICA, monitoring trends and determinants in cardiovascular disease; NSF, National Service Framework; $\mathrm{PCl}$, percutaneous coronary intervention; PRAIS-UK, prospective registry of acute ischaemic syndromes in the UK 
Table 1 Summary of acute coronary syndrome guidelines applicable to British patients

\begin{tabular}{|c|c|c|c|c|c|c|c|}
\hline \multicolumn{4}{|l|}{ ST elevation MI } & \multicolumn{4}{|c|}{ Non-ST elevation MI/unstable angina } \\
\hline Treatment & BCS & $\mathrm{ESC}^{*}$ & NSF† & Treatment & BCS $\ddagger$ & ESC§ & NSF† \\
\hline Initial & $\begin{array}{l}\text { Aspirin, } \\
\text { thrombolysis/ } \\
\text { PCI }\end{array}$ & $\begin{array}{l}\text { Aspirin, } \\
\text { thrombolysis/PCl }\end{array}$ & $\begin{array}{l}\text { Aspirin, } \\
\text { thrombolysis }\end{array}$ & For low risk & $\begin{array}{l}\text { Aspirin, LMWH, } \\
\text { nitrates, } \\
\beta \text { blockers }\end{array}$ & $\begin{array}{l}\text { Aspirin, } \mathrm{LMWH} \text {, } \\
\text { nitrates, } \beta \text { blockers, } \\
\text { clopidogrel }\end{array}$ & $\begin{array}{l}\text { Aspirin, } \\
\text { unfractionated } \\
\text { heparin or LMWH, } \\
\beta \text { blocker, nitrates }\end{array}$ \\
\hline Subsequent & $\beta$ Blocker & $\begin{array}{l}\beta \text { Blocker, } \\
\mathrm{ACEI}<24 \text { hours }\end{array}$ & $\begin{array}{l}\beta \text { Blocker, } \\
\text { ACEI }\end{array}$ & For high risk & $\begin{array}{l}\text { GP Ilb/Illa, } \\
\text { angiogram } \\
\text { (also } \\
\text { intermediate risk) }\end{array}$ & $\begin{array}{l}\text { GP Ilb/Illa, } \\
\text { angiogram }\end{array}$ & Angiogram \\
\hline On discharge & $\begin{array}{l}\text { Aspirin, } \beta \text { blocker, } \\
\text { statin }\end{array}$ & $\begin{array}{l}\text { Aspirin (clopidogrel } \\
\text { if aspirin } \\
\text { contraindicated), } \\
\beta \text { blocker, statin }\end{array}$ & $\begin{array}{l}\text { Aspirin, } \\
\beta \text { blocker, statin }\end{array}$ & On discharge & $\begin{array}{l}\text { Aspirin, } \\
\beta \text { blocker, statin }\end{array}$ & $\begin{array}{l}\text { Aspirin, clopidogrel } \\
\text { (for at least } 9 \\
\text { months), } \beta \text { blocker, } \\
\text { statin }\end{array}$ & $\begin{array}{l}\text { Aspirin, } \beta \text { blocker, } \\
\text { statin }\end{array}$ \\
\hline
\end{tabular}

*Published 2003; tpublished 2000; fpublished 2001; spublished 2002.

ACEI, angiotensin converting enzyme inhibitor; BCS, British Cardiac Society; ESC, European Society of Cardiology; GP, glycoprotein; LMWH, low molecular weight heparin; MI, myocardial infarction; NSF, National Service Framework; PCl, percutaneous coronary intervention.

To what extent does management of ACS in the UK reflect these evidence based guidelines and the recommendations of the NSF on coronary artery disease (released in 2000), the Scottish Intercollegiate Guidelines Network guidelines, ${ }^{9}$ or the European guidelines (European Society of Cardiology, 2002, 2003)? The large, international GRACE (global registry of acute coronary events) registry provides an opportunity to test this question. Thus, we have used data from GRACE to compare standards of care for ACS (both ST and non-ST elevation) between the UK and other countries. GRACE provides a unique opportunity to determine the extent to which current practice in the UK, and among comparator countries, meets key elements of the guidelines for the management of ACS.

\section{METHODS}

GRACE is a prospective, international, observational registry, designed to enrol patients with ACS in an unbiased approach and to collect data representative of respective geographic populations. GRACE involves 94 hospitals in 14 countries and we report the findings from the first 1511 patients from the UK. It compares management and outcome with contemporaneous data from other European countries: Austria, Belgium, France, Germany, Italy, Poland, and Spain (European group); and countries elsewhere in the world: Argentina, Australia, Brazil, Canada, USA, and New Zealand (multinational group).The hospitals in a geographic region are grouped as a cluster and include the full range of hospitals admitting patients with ACS for the respective communities. For the UK cluster all of the hospitals for the defined geographic population in the southeast of Scotland participated in GRACE. An analogous geographic cluster approach was adopted in the MONICA (monitoring trends and determinants in cardiovascular disease) study. ${ }^{10}$ GRACE uses prospectively defined disease classifications and has a six month follow up. Full details of the design and methods have previously been published. ${ }^{11}$

\section{Patient identification}

GRACE enrolled patients admitted with a working diagnosis of unstable angina or suspected MI (with or without ST segment deviation).

The catchment population for the British cohort of 1511 patients (the number of British patients enrolled at the time of analysis) is estimated to be $950000,{ }^{12}$ and the cluster comprises all of the four hospitals admitting patients with ACS in the geographic region. Three are teaching hospitals and of these two have onsite cardiac catheterisation laboratories, one with a cardiac surgical service. The remaining hospital is a large district general hospital.

Criteria for inclusion into GRACE are presentation to hospital with suspected ACS as the admitting diagnosis in a patient over 18 years of age and admitted alive. If the presenting ACS was thought to have been precipitated by unrelated co-morbidity, such as trauma, the patient would not be eligible. Similarly, patients already admitted for another indication were not eligible. Transfer patients were

Table 2 Key baseline characteristics for UK, Europe, and multinational groups of patients with acute coronary syndromes by baseline condition

\begin{tabular}{|c|c|c|c|c|c|c|c|c|c|}
\hline & \multicolumn{3}{|c|}{ ST elevation MI } & \multicolumn{3}{|c|}{ Non-ST elevation MI } & \multicolumn{3}{|c|}{ Unstable angina } \\
\hline & $\begin{array}{l}\text { UK } \\
(n=390)\end{array}$ & $\begin{array}{l}\text { Eur } \\
(n=2729)\end{array}$ & $\begin{array}{l}M N \\
(n=3696)\end{array}$ & $\begin{array}{l}\text { UK } \\
(n=376)\end{array}$ & $\begin{array}{l}\text { Eur } \\
(n=1602)\end{array}$ & $\begin{array}{l}M N \\
(n=4111)\end{array}$ & $\begin{array}{l}\text { UK } \\
(n=605)\end{array}$ & $\begin{array}{l}\text { Eur } \\
(n=2174)\end{array}$ & $\begin{array}{l}\text { MN } \\
(n=4457)\end{array}$ \\
\hline Age (years)* & $64(12)$ & $64(13)$ & $63(14)$ & $66(12)$ & 67 (12) & 67 (13) & $66(11)$ & 66 (12) & $66(12)$ \\
\hline Men & $68 \%$ & $72 \%$ & $71 \%$ & $67 \%$ & $68 \%$ & $61 \%$ & $62 \%$ & $65 \%$ & $61 \%$ \\
\hline $\begin{array}{l}\text { Participant in a } \\
\text { clinical trial } \\
\text { Cardiac }\end{array}$ & $8 \%$ & $6 \%$ & $9 \%$ & $5 \%$ & $4 \%$ & $5 \%$ & $6 \%$ & $11 \%$ & $4 \%$ \\
\hline catheterisation & $6 \%$ & $7.3 \%$ & $14 \%$ & $17 \%$ & $17 \%$ & $27 \%$ & $40 \%$ & $24 \%$ & $41 \%$ \\
\hline Diabetes & $11 \%$ & $20 \%$ & $24 \%$ & $11 \%$ & $20 \%$ & $29 \%$ & $14 \%$ & $21 \%$ & $29 \%$ \\
\hline Hypertension & $36 \%$ & $48 \%$ & $54 \%$ & $36 \%$ & $56 \%$ & $65 \%$ & $45 \%$ & $61 \%$ & $70 \%$ \\
\hline Hyperlipidaemia & $26 \%$ & $34 \%$ & $40 \%$ & $27 \%$ & $40 \%$ & $49 \%$ & $49 \%$ & $45 \%$ & $56 \%$ \\
\hline Current smoking & $49 \%$ & $40 \%$ & $34 \%$ & $49 \%$ & $26 \%$ & $23 \%$ & $30 \%$ & $21 \%$ & $19 \%$ \\
\hline (days) & $6 \%$ & $10 \%$ & $8 \%$ & $6 \%$ & $10 \%$ & $8 \%$ & $5 \%$ & $9 \%$ & $7 \%$ \\
\hline
\end{tabular}

*Mean (SD).

Eur, European; MN, multinational. 

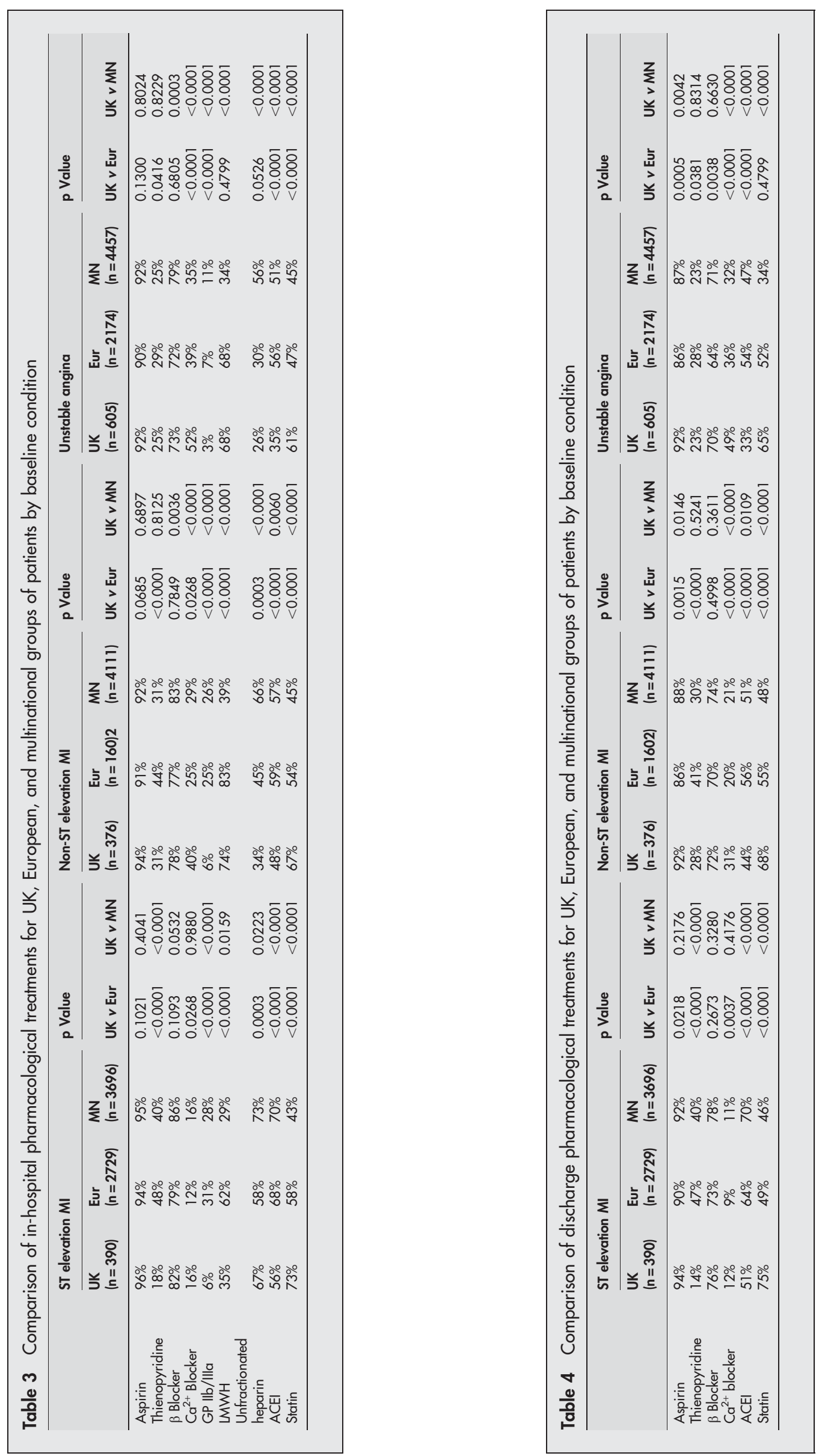


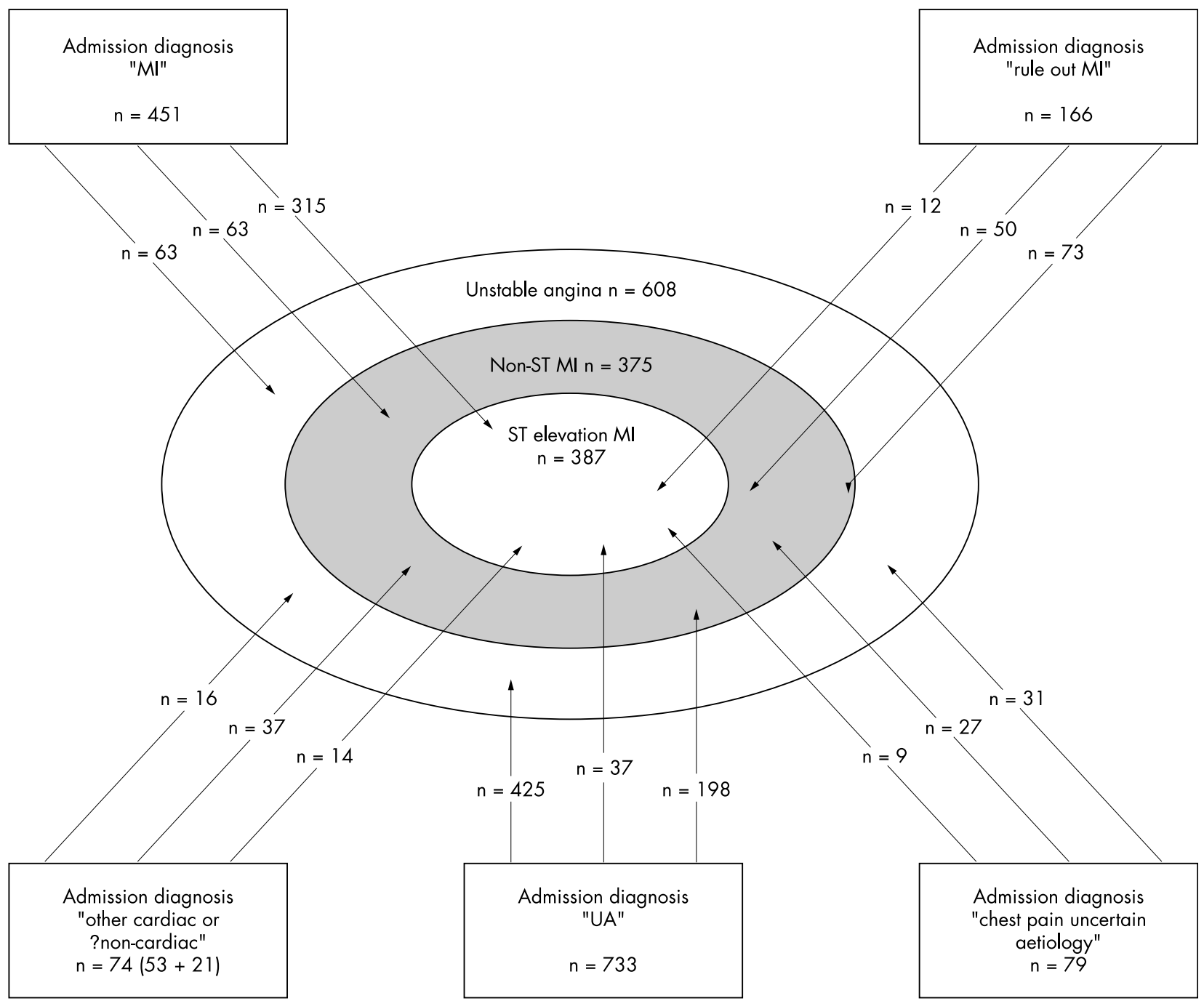

Figure 1 Patients with acute coronary syndromes: initial and final diagnoses. MI, myocardial infarction; UA, unstable angina.

included regardless of the time spent at the transferring hospital. The study received ethical approval and all patients gave written consent. Special permission was granted from the ethical committees to allow key data to be captured without written consent for patients suspected to be moribund on arrival (specific patient identifying characteristics

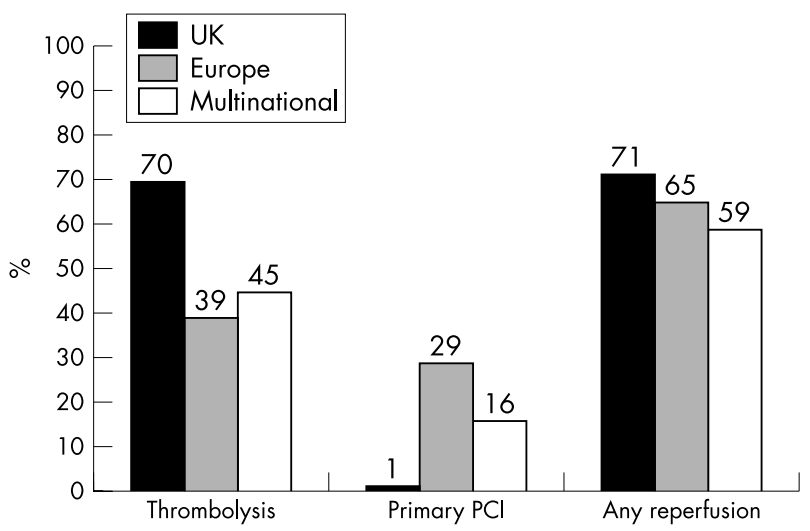

Figure 2 Comparison of in-hospital reperfusion by baseline condition for UK, European, and multinational groups of patients with ST elevation $\mathrm{MI}$. $\mathrm{PCl}$, percutaneous coronary intervention. were not recorded on the electronic database for such patients). Patients were classified on discharge according to prespecified criteria as having ST elevation MI, non-ST elevation MI, or unstable angina (no marker detectable). ${ }^{11}$ Patients were followed up six months after hospital discharge.

\section{Data collection}

Patients were identified during their hospital admission and data were abstracted by trained study coordinators. All sites

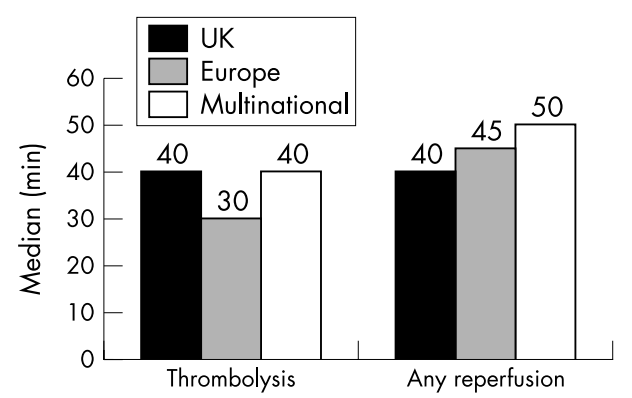

Figure 3 Median time from hospital arrival to reperfusion for UK, European, and multinational groups of patients with ST elevation MI. 


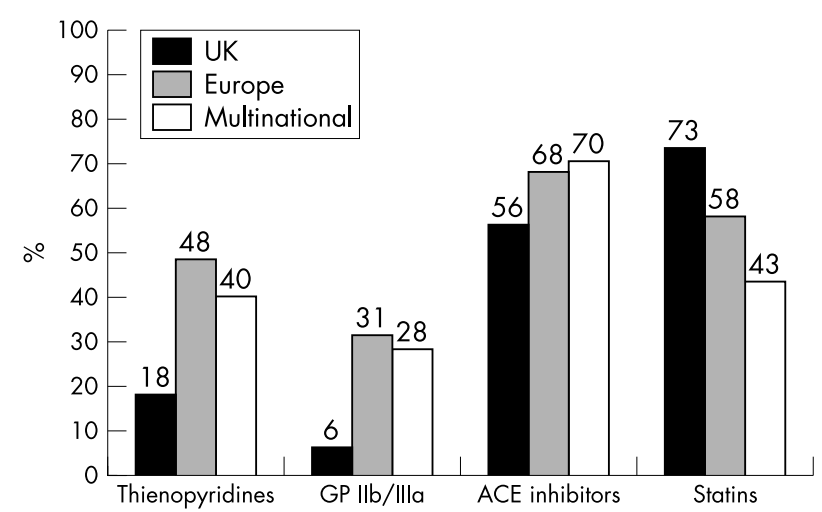

Figure 4 Key points from comparison of in-hospital pharmacological treatments for UK, European, and multinational groups of patients with ST elevation MI. ACE, angiotensin converting enzyme; GP, glycoprotein.

received prospective training before commencing the study. Each participating hospital enrolled the first 10 to 20 patients (depending on hospital size) admitted each month with ACS. The target number of patients for a hospital was determined by the frequency of discharge diagnosis of ACS for that hospital. Once the standardised case record form was completed, the data were sent by fax or electronically to the data collection centre in Philadelphia in the USA. Data were analysed by the Centers For Outcomes Research Group of the University of Massachusetts under the steering committee chairmanship of Professor KAA Fox (University of Edinburgh) and Dr J Gore (University of Massachusetts). The quality and validity of the data collected in each of the participating hospitals were checked by a programme of random local audits.

\section{Statistical methods}

This report describes the first 1511 patients recruited from the UK and compares them with patients enrolled elsewhere in Europe and in selected countries in the rest of the world (multinational group). The differences in the distribution of demographic and clinical characteristics, medical management, and in-hospital outcomes were examined by $\chi^{2}$ tests for discrete variables; Wilcoxon rank sum tests were used to examine differences between the groups for continuous variables. Multiple logistic regression analyses were used to estimate the adjusted rates for the in-hospital outcome of mortality in each of the three geographic regions (UK, Europe, and multinational). Adjusted rates of mortality were

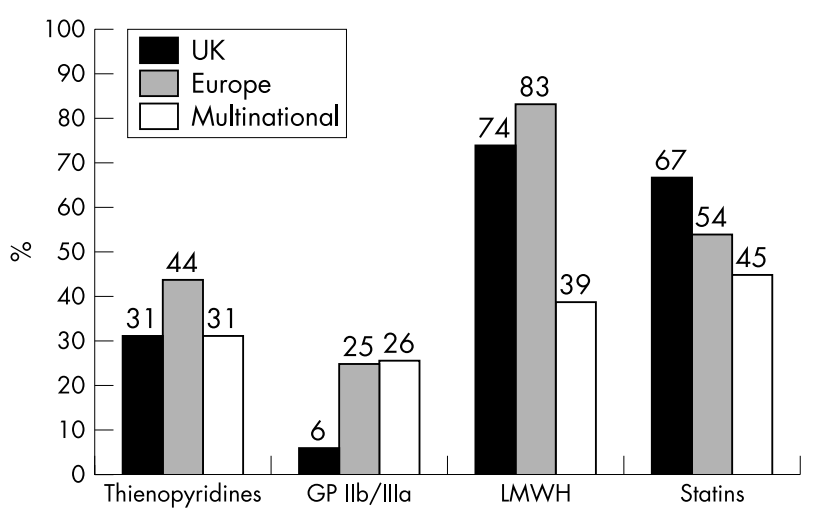

Figure 5 Key points from comparison of in-hospital pharmacological treatments for UK, European, and multinational groups of patients with non-ST elevation MI. LMWH, low molecular weight heparin.

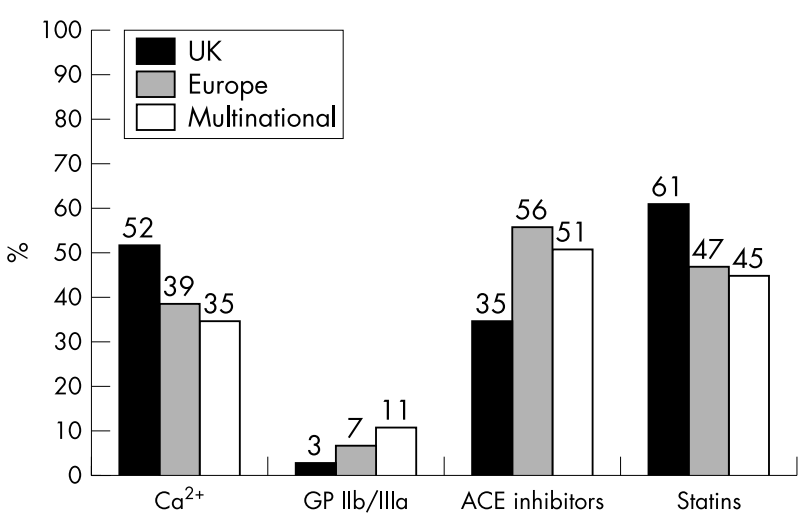

Figure 6 Key points from comparison of in-hospital pharmacological treatments for UK, European, and multinational groups of patients with unstable angina.

also calculated by the same methods for the period six months after discharge from hospital. We used the variables from the GRACE risk model. ${ }^{13}$ Differences between the adjusted rates were examined by $\chi^{2}$ test. All the tests used in this study were double sided and considered significant at $\alpha<0.05$. The statistical analyses were calculated with a SAS software package (version 8.2, SAS Institute, Cary, North Carolina, USA).

\section{RESULTS}

\section{Demographic characteristics}

The British study population of 1511 patients was admitted to the UK cluster hospitals during the defined sampling interval (June 1999 to March 2002). During the same sampling interval 6505 patients with ACS were admitted to the cluster hospitals in Austria, Belgium, France, Germany, Italy, Poland, and Spain (excluding the UK) and 12264 patients with ACS were admitted to cluster hospitals in Argentina, Australia, Brazil, Canada, USA, and New Zealand. A separate analysis indicated that the British hospitals met $92 \%$ of the target recruitment during this collection period and completeness of followed up at six months was $98 \%$. Table 2 shows the baseline characteristics.

\section{How accurate are admission working diagnoses of ACS?}

Of the 1511 patients enrolled with suspected admission diagnoses of ACS, unstable angina was the working diagnosis on admission for $733(49 \%)$, MI was the working diagnosis for $451(30 \%), 166$ (11\%) were admitted "to rule out an MI", 79 (5\%) had chest pain of uncertain aetiology, 53 (4\%) had "other cardiac" diagnoses, and 21 (1\%) had "non-cardiac" diagnoses (fig 1). Admission diagnoses were missing for eight patients. The key findings can be summarised as follows:

- The likelihood of progression to MI from admission diagnosis of suspected MI is high: 315 of 451 patients with an admission diagnosis of MI progressed to ST elevation MI and 63 progressed to non-ST MI. Thus, the working diagnosis of MI was confirmed in $84 \%$ (378 of 451)

- Only a small proportion of patients with an admission diagnosis of unstable angina $(5 \%, 37$ of 733$)$ progressed to a final diagnosis of ST elevation MI, but a larger proportion $(27 \%, 198$ of 733$)$ of patients with an admission diagnosis of unstable angina progressed to non-ST elevation MI 
Table 5 Comparison of in-hospital cardiac procedures for UK, European, and multinational groups of patients by baseline condition

\begin{tabular}{|c|c|c|c|c|c|c|c|c|c|}
\hline \multirow[b]{2}{*}{$\begin{array}{l}\text { Cardiac } \\
\text { procedure }\end{array}$} & \multicolumn{3}{|c|}{ ST elevation MI } & \multicolumn{3}{|c|}{ Non-ST elevation MI } & \multicolumn{3}{|c|}{ Unstable angina } \\
\hline & $\begin{array}{l}\text { UK } \\
(n=390)\end{array}$ & $\begin{array}{l}\text { Eur } \\
(n=2729)\end{array}$ & $\begin{array}{l}M N \\
(n=3696)\end{array}$ & $\begin{array}{l}\text { UK } \\
(n=376)\end{array}$ & $\begin{array}{l}\text { Eur } \\
(n=1602)\end{array}$ & $\begin{array}{l}\text { MN } \\
(n=41111)\end{array}$ & $\begin{array}{l}\text { UK } \\
(n=605)\end{array}$ & $\begin{array}{l}\text { Eur } \\
(n=2174)\end{array}$ & $\begin{array}{l}M N \\
(n=4457)\end{array}$ \\
\hline $\begin{array}{l}\text { Cardiac } \\
\text { catheterisation }\end{array}$ & $20 \%$ & $53 \%$ & $63 \%$ & $31 \%$ & $58 \%$ & $57 \%$ & $28 \%$ & $37 \%$ & $50 \%$ \\
\hline $\mathrm{PCl}$ & $13 \%$ & $47 \%$ & $43 \%$ & $20 \%$ & $37 \%$ & $28 \%$ & $17 \%$ & $21 \%$ & $20 \%$ \\
\hline Primary $\mathrm{PCl}$ & $1 \%$ & $29 \%$ & $16 \%$ & NA & NA & NA & NA & NA & NA \\
\hline CABG & $1 \%$ & $3 \%$ & $6 \%$ & $2 \%$ & $5 \%$ & $12 \%$ & $2 \%$ & $3 \%$ & $8 \%$ \\
\hline
\end{tabular}

- The largest degree of uncertainty with working diagnoses on admission is in a diagnosis of unstable angina and of unspecified but suspected ACS.

\section{Geographic differences in practice \\ ST elevation MI and reperfusion}

The frequency of thrombolytic treatment was highest in the UK $(70 \%)$ in comparison with the European (39\%) and multinational $(45 \%)$ groups. The findings were in striking contrast to the practice of primary PCI, which was lowest in the UK ( $1 \%$ ) compared with $29 \%$ in the European group and $16 \%$ in the multinational group. Nevertheless, when any type of reperfusion was considered (either thrombolysis or primary PCI) the UK had the overall highest rate of reperfusion treatment in comparison with the European and multinational groups $(71 \%, 65 \%$, and $59 \%$ respectively, $\mathrm{p}=0.0128, \mathrm{p} \leqslant 0.0001$ ) (fig 2 ). Delay time from hospital arrival to reperfusion with thrombolysis was 40 minutes in the UK (median), identical to the delay for multinational patients but longer than that for the European group (median time 30 minutes) (fig 3).

\section{Other pharmacological treatments in ST elevation MI}

Use of thienopyridines for patients with a discharge diagnosis of ST elevation MI differed greatly between the UK, European, and multinational groups (a treatment not yet recommended in guidelines for ST elevation MI). The UK had the lowest use of thienopyridines (18\%) in comparison with the European and multinational groups (48\% and $40 \%$, respectively). Glycoprotein IIb/IIIa inhibitor use by patients with ST elevation MI was substantially lower in the UK $(6 \%$; $31 \%$ Europe and 28\% multinational). A smaller gradient for in-hospital prescribing of ACE inhibitors was seen $(56 \%, 68 \%$, and $70 \%$, respectively). In contrast, in-hospital prescribing of statins was highest in the UK (73\%) compared with the European (58\%) and multinational groups (43\%) (fig 4, table 3).
At discharge ACE inhibitors were used in $(51 \%$ v $64 \%$ and $70 \%$, respectively). However, the UK prescribed statins more often to patients with ST elevation MI at hospital discharge than either the European or multinational groups (75\%, 49\%, and $46 \%$, respectively; table 4 ).

\section{Non-ST elevation MI}

Although the proportion of patients in this group prescribed aspirin was similar regardless of geographical region, differences were observed in use of thienopyridines. The UK and the multinational groups prescribed thienopyridines with similar frequency $(31 \%)$ but this was lower than elsewhere in Europe $(44 \%)$. Glycoprotein IIb/IIIa inhibitors were prescribed infrequently in the UK in comparison with European and multinational groups (6\% UK, 25\% Europe, and 26\% multinational). Use of low molecular weight heparin was noted to be high in both the UK and European groups in contrast to the multinational group $(74 \%, 83 \%$, and $39 \%$, respectively) and use of statins was also highest in the UK $(67 \%)$ in comparison with European $(54 \%)$ and multinational (45\%) groups (fig 5). The UK had the lowest percentage of patients taking thienopyridines on discharge $(28 \%)$ but the highest percentage of patients taking calcium channel blockers on discharge (31\% UK, 20\% Europe, 21\% multinational).

\section{Unstable angina}

As for non-ST elevation MI, calcium channel blockers were prescribed more often in the UK for patients with unstable angina than elsewhere (52\% UK, 39\% Europe, and 35\% multinational). Glycoprotein IIb/IIIa inhibitors were least prescribed in the UK (3\% UK, 7\% Europe, and 11\% multinational) but use of statins during the in-hospital admission was highest in the UK group $(61 \%)$ in comparison with the European (47\%) and multinational groups (45\%) (fig 6).

In a similar pattern to that seen for non-ST elevation MI, calcium channel blockers $(49 \%, 36 \%, 32 \%)$, and statins $(65 \%$, $52 \%, 34 \%$ ) were prescribed more often on discharge for patients with unstable angina in the UK than in the other geographic regions (table 4).

\begin{tabular}{|c|c|c|c|c|c|}
\hline & UK & Eur & $\begin{array}{l}\text { p Value } \\
\text { UK } v \text { Eur }\end{array}$ & MN & $\begin{array}{l}\text { p Value } \\
\text { UK } v \text { MN }\end{array}$ \\
\hline \multicolumn{6}{|l|}{ ST elevation MI } \\
\hline Death crude & 26 (6.7\%) & $236(7.8 \%)$ & 0.4049 & $267(8.0 \%)$ & 0.4111 \\
\hline Death adjusted & $8.1 \%$ & $7.2 \%$ & 0.0571 & $7.4 \%$ & 0.1156 \\
\hline \multicolumn{6}{|c|}{ Non-ST elevation MI } \\
\hline Death crude & $19(5.1 \%)$ & $121(6.7 \%)$ & 0.2828 & $194(5.1 \%)$ & 0.9699 \\
\hline Death adjusted & $5.2 \%$ & $5.9 \%$ & 0.0844 & $4.9 \%$ & 0.4333 \\
\hline \multicolumn{6}{|l|}{ Unstable angina } \\
\hline Death crude & $11(1.8 \%)$ & $82(3.5 \%)$ & 0.0298 & 131 (3.1\%) & 0.1070 \\
\hline Death adjusted & $1.6 \%$ & $2.0 \%$ & 0.1196 & $2.6 \%$ & $<0.0001$ \\
\hline
\end{tabular}




\begin{tabular}{|c|c|c|c|c|c|}
\hline & UK & Eur & $\begin{array}{l}\text { p Value } \\
\text { UK } v \text { Eur }\end{array}$ & MN & $\begin{array}{l}\text { p Value } \\
\text { UK } v \text { MN }\end{array}$ \\
\hline \multicolumn{6}{|l|}{ ST elevation MI } \\
\hline Death crude & $21(6.1 \%)$ & $86(4.0 \%)$ & 0.0781 & $137(5.2 \%)$ & 0.4991 \\
\hline Death adjusted & $7.2 \%$ & $4.3 \%$ & $<0.0001$ & $5.3 \%$ & $<0.0001$ \\
\hline \multicolumn{6}{|c|}{ Non-ST elevation MI } \\
\hline Death crude & $22(6.4 \%)$ & $80(6.1 \%)$ & 0.8058 & $210(6.7 \%)$ & 0.8377 \\
\hline Death adjusted & $7.5 \%$ & $6.2 \%$ & 0.0123 & $6.7 \%$ & 0.1419 \\
\hline \multicolumn{6}{|l|}{ Unstable angina } \\
\hline Death crude & 22 (3.9\%) & $62(3.6 \%)$ & 0.7573 & $145(4.1 \%)$ & 0.7991 \\
\hline Death adjusted & $3.8 \%$ & $3.2 \%$ & 0.0896 & $4.5 \%$ & 0.0533 \\
\hline
\end{tabular}

\section{Revascularisation procedures}

The UK had the lowest rates of coronary angiography and coronary angioplasty for each ACS category (table 5). In the UK 13\% of patients with ST elevation MI received a PCI compared with $47 \%$ in Europe and $43 \%$ of multinational patients. The proportions of patients with non-ST elevation MI undergoing a PCI were $20 \%$ in the UK, $37 \%$ in Europe, and $28 \%$ multinationally. In the UK patients with unstable angina were half as likely as multinational patients to undergo a cardiac catheterisation. Similarly, the number of coronary artery bypass graft operations was also lowest in the UK. However, once angiography had been performed the proportion of patients progressing to PCI was similar in the UK and elsewhere, at $17 \%, 21 \%$, and $20 \%$, respectively (table 5).

\section{Outcomes}

In-hospital and post-discharge outcomes were compared for the UK, European, and multinational groups by calculating crude and adjusted death rates for the ST elevation MI, nonST elevation MI, and unstable angina groups and then adjusting for baseline risk by applying the GRACE risk score. $^{13}$

After risk adjustment for differences in baseline variables the in-hospital death rate for the UK ACS cohorts was not significantly different for ST elevation and non-ST elevation MI but was lower for unstable angina (table 6). In contrast, after risk adjustment the post-discharge adjusted death rates were higher for ST elevation MI and non-ST elevation MI (table 7).

\section{DISCUSSION}

The use of a standardised selection method and case definition for inclusion of patients into GRACE allows a novel comparison with combined data from other European countries and with specific comparator countries worldwide.

The key results from the UK data are as follows:

- Although a high rate of confirmation of MI was observed among patients with a working diagnosis of ST elevation MI on admission, for non-ST elevation MI fewer than one fifth had suspected MI on arrival. For unstable angina only half were classified to have suspected unstable angina on admission (58\%)

- In ST elevation MI, the UK had the highest rate of reperfusion, although this was achieved almost entirely by thrombolysis, rather than primary PCI

- Major differences exist between the UK and elsewhere in in-hospital pharmacological treatments. Thienopyridines, glycoprotein IIb/IIIa inhibitors, and ACE inhibitors are prescribe less often in the UK than in other European countries and multinationally
- The UK prescribes the highest proportion of statins for the whole spectrum of ACS and the highest proportion of calcium antagonists

- Death rates after baseline risk adjustment were higher at six months after discharge in the UK among patients with ST elevation MI and non-ST elevation MI (table 7).

This study provides an opportunity to compare the working diagnosis on admission with the final diagnosis at the time of hospital discharge. Figure 1 illustrates that ST elevation MI is the component of ACS most often correctly identified at the time of admission with $84 \%$ of patients having their diagnosis of ST elevation MI confirmed by discharge. In contrast, only $17 \%$ of patients with non-ST elevation MI were correctly identified to have suspected infarction, suggesting a need to improve early diagnostic testing for this condition. Over one third of patients with an admission diagnosis of "rule out MI" were proved to have had an MI by discharge and, for the remainder, unstable angina was the final diagnosis for $70 \%$. More than two thirds of patients who presented with suspected ACS but had a working diagnosis of either other cardiac or non-cardiac conditions were found to have had an acute coronary event by discharge.

The rates of reperfusion were highest in the UK $(71 \% v 65 \%$ in the European and $59 \%$ in the multinational groups; $\mathrm{p}<0.01)$. However, reperfusion in the UK was almost exclusively with lytic treatment in contrast to the other groups. Although a substantial proportion of patients did not receive reperfusion, patients with contraindications have not been excluded from this analysis. We have previously reported that certain higher risk groups do not receive reperfusion-for example, the elderly and patients with atypical presentation or with heart failure. ${ }^{14}$

The high frequency of prescribing statins and of calcium antagonists in unstable angina and the high rates of thrombolysis may be a result of targets set by the NSF. This framework recommends that all patients with ACS should be prescribed a statin to either lower their cholesterol to $<5.0 \mathrm{mmol} / \mathrm{l}$ or reduce it by $30 \% .{ }^{8}$ It also states that patients with unstable angina should receive a calcium antagonist as additional treatment unless contraindicated, but this is not evidence based. ${ }^{8}$ The NSF and the current Scottish Intercollegiate Guidelines Network guidelines also recommend that patients with acute MI should be treated with thrombolysis and does not specify the option of performing reperfusion by primary PCI. ${ }^{89}$ Current practice in managing patients with ACS in the UK relates more closely to the recommendations of the NSF than to the guidelines set by the task forces of the European Society of Cardiology ${ }^{3}{ }^{4}$ and of the British Cardiac Society. ${ }^{2}$

Although in-hospital death rates did not differ significantly (table 6), by six months after discharge the death rates in the UK (risk adjusted) were significantly higher than in either 
the European or multinational groups for ST elevation MI and significantly higher than in the European group for nonST elevation MI (table 7). This may be due, at least in part, to primary PCI being practised more widely during hospitalisation in the European and multinational groups, earlier thrombolysis in Europe, and differences in pharmacological treatments. In ST elevation and non-ST elevation MI the UK prescribed intravenous glycoprotein IIb/IIIa inhibitors and thienopyridines significantly less often, but neither of these pharmacological agents is part of current European or British guidelines for the treatment of ST elevation MI with a lytic agent.

\section{How do the findings compare with previous multinational registries?}

The ENACT survey was conducted in 1999 and involved 17 European countries. ${ }^{6}$ ENACT measured the prevalence and treatment of ACS with a once only data retrieval from 10 patients admitted consecutively to each of the participating hospitals. The hospitals were not necessarily geographically representative and there was no follow up. In 1998 the PRAIS-UK registry consisted of 1046 patients with an ACS (but without ST elevation MI) and provided information on treatment and practice within the UK. ${ }^{7}$

GRACE provides a representative sample of ACS, but caution must be exercised in extrapolating results from a geographic cluster of hospitals to a wider region or country. Nevertheless, a similar approach has been adopted in the MONICA study. ${ }^{10}$ The study design of GRACE aims to provide a robust sample that encompasses the full spectrum of hospitals admitting patients with ACS and to implement measures to avoid recruitment bias. ${ }^{11}{ }^{13}$

In 2001, the Euro heart survey of acute coronary syndromes collected data from 10484 patients with ACS, ${ }^{15}$ but the data are not necessarily representative of geographic regions and no country specific data have been published. Nevertheless, examining overall European data, there are similarities between the findings of GRACE and the Euro heart survey. The proportion of patients taking aspirin $(90 \% \mathrm{~V}$ $89 \%), \beta$ blockers (73\% v 76\%), calcium channel blockers $(9 \%$ $v 10 \%$ ), ACE inhibitors (64\% v 63\%), and statins ( $49 \%$ v 54\%) on discharge were similar. However, in GRACE a higher proportion of patients were taking thienopyridines on discharge after ST elevation MI (47\% v 36\%) and after nonST elevation MI (41\% v 25\%). Rates of coronary angiography and PCI were comparable between the GRACE ST elevation European group and the Euro heart survey $(53 \% v 56 \%$ for angiography and $47 \% \vee 40 \%$ for PCI), but the frequency of PCI in non-ST elevation MI was lower in the Euro heart survey $(25 \% v 37 \%)$. GRACE's data are more recent (up to March 2002) and differences in angiography and PCI may reflect trends over time. However, as shown by these GRACE UK data, similarities in pooled European registry information on the management of ACS may obscure important geographic differences in practice.

The findings from GRACE indicate that $75 \%$ of British patients are now taking a statin on discharge compared with $16 \%$ of patients with acute MI who participated in the ASPIRE (action on secondary prevention through intervention to reduce events) survey, published in $1996 .^{16} 17$ Directionally similar increases were seen in the Euro heart survey of acute coronary syndromes in $2002 .{ }^{15}$

\section{Conclusions}

GRACE provides the opportunity to describe the pattern of management and outcome for patients with ACS and to compare the UK with contemporaneous management elsewhere in Europe and multinationally.
Although a working diagnosis of ST elevation MI on admission is remarkably accurate, substantial uncertainty exists in making the diagnosis of non-ST elevation MI or unstable angina. Improved diagnostic and risk stratification methods are required.

The patterns of management of ACS in the UK most closely relate to the NSF recommendations rather than to British or European guidelines. In particular, higher risk patients with ACS are less often treated with more potent antiplatelet treatment and PCI than elsewhere in Europe or multinationally.

Although differences in outcome are not apparent during hospitalisation, by six months' follow up the UK has higher rates of death for ST elevation MI and non-ST elevation MI, even after adjustment for baseline risks. These differences in outcome may be due, at least in part, to the observed differences in pharmacological and interventional treatment.

\section{ACKNOWLEDGEMENTS}

The GRACE Investigators thank all the physicians and nurses who are participating in GRACE.

GRACE is supported by an unrestricted educational grant from Aventis Pharma.

To find out more about GRACE, visit the website at www.outcomes. org/grace.

GRACE Steering Committee and Co-chairmanship: Keith AA Fox, Joel M Gore (GRACE Co-Chairs); Kim A Eagle, Ph Gabriel Steg (Publication Committee Co-Chairs); Giancarlo Agnelli, Frederick A Anderson Jr, Alvaro Avezum, David Brieger, Andrzej Budaj, Marcus D Flather, Robert J Goldberg, Shaun G Goodman, Christopher B Granger, Dietrich C Gulba, Enrique P Gurfinkel, Brian M Kenelly, Werner Klein, Jose Lopez-Sendon, Gilles Montalescot, Frans Van de Werf.

\section{Authors' affiliations}

K F Carruthers, K A A Fox, The University and The Royal Infirmary of Edinburgh, Edinburgh, UK

O H Dabbous, University of Massachusetts Medical School, Worcester, Massachusetts, USA

M D Flather, Royal Brompton and Harefield NHS Trust, London, UK

I Starkey, The Western General Hospital, Edinburgh, UK

A Jacob, St John's Hospital, Livingston, UK

D MacLeod, Queen Margaret Hospital, Dunfermline, UK

\section{REFERENCES}

1 Petersen S, Rayner M. Coronary heart disease statistics. British Heart Foundation statistics database. London: British Heart Foundation, 2002.

2 Anon. British Cardiac Society Guidelines and Medical Practice Committee, Royal College of Physicians Clinical Effectiveness and Evaluation Unit. Heart 2001;85:133-42.

3 Bertrand ME, Simoons ML, Fox KAA, et al. Management of acute coronary syndromes in patients presenting without persistent ST-segment elevation. Eur Heart J 2002;23:1809-40.

4 Van de Werf F, Ardissino D, Betriu A, et al. Management of acute myocardial infarction in patients presenting with ST-segment elevation. Eur Heart $J$ 2003;24:28-66.

5 Braunwald E, Antman EM, Beasley JW, et al. ACC/AHA 2002 guideline update for the management of patients with unstable angina and non-ST segment elevation myocardial infarction: a report of the American College of Cardiology/American Heart Association Task Force on Practice Guidelines (Committee on the Management of Patients with Unstable Angina). 2002. www.acc.org/clinical/guidelines/unstable/unstable.pdf /accessed 4 August 2004).

6 Fox KAA, Cokkinos DV, Deckers J, et al. The ENACT study: a pan-European survey of acute coronary syndromes. Eur Heart J 2000;21:1440-9.

7 Collison J, Flather MD, Fox KAA, et al. Clinical outcomes, risk stratification and practice patterns of unstable angina and myocardial infarction without ST elevation: prospective registry of acute ischemic syndromes in the UK (PRAISUK). Eur Heart J 2000;21:1450-7.

8 Adam S. National service framework for coronary heart disease, HSC 2000/ 012. 4 April 2000. www.dh.gov.uk/assetRoot/04/01/22/52/ 04012252.pdf (accessed 4 August 2004).

9 SIGN. Clinical guidelines. Scottish Intercollegiate Guidelines Network. www.sign.ac.uk/guidelines (accessed 4 August 2004).

10 Chambless L, Keil U, Dobson A, et al. Population $v$ clinical view of case fatality from acute coronary heart disease. Results from the WHO MONICA project 1985-1990. Circulation 1997;96:3849-59. 
11 GRACE Investigators. GRACE (global registry of acute coronary events): a multinational registry of patients hospitalized with acute coronary syndromes The GRACE investigators. Am Heart J 2001;141:190-9.

12 Anon. scrol: Scotland's census results online. www.scrol.gov.uk/scrol/ common/home.jsp (accessed 4 August 2004).

13 Granger CB, Goldberg RJ, Dabbous OM, et al. Predictors of hospital mortality in the global registry of acute coronary events. Arch Intern Med 2003; 163:2345-53.

14 Eagle KA, Goodman SG, Avezum A, et al. Practice variation and missed opportunities for reperfusion in ST-segment-elevation myocardial infarction: findings from the global registry of acute coronary events (GRACE). Lancet 2002;359:373-7.
15 Hasdai D, Behar S, Wallentin L, et al. A prospective survey of the characteristics, treatments and outcomes of patients with acute coronary syndromes in Europe and the Mediterranean basin: the Euro heart survey of acute coronary syndromes (Euro heart survey ACS). Eur Heart $J$ 2002; 23:1190-201.

16 Bowker TJ, Clayton TC, Ingham J, et al. A British Cardiac Society survey of the potential for the secondary prevention of coronary disease: ASPIRE (action on secondary prevention through intervention to reduce events). Heart 1996;75:334-42.

17 EUROASPIRE Study Group. EUROASPIRE. A European Society of Cardiology survey of secondary prevention of coronary heart disease: principal results. Eur Heart J 1997; 18:1569-82.

\section{IMAGES IN CARDIOLOGY}

\section{Pneumopericardium presenting as reduced ECG voltages}

A 13 year old boy presented with a one week history of cough, coryza, and shortness of breath on minimal exertion. A murmur was noted, and an echocardiogram revealed a structurally normal heart with a large pericardial effusion. A pericardial drain was inserted percutaneously and $700 \mathrm{ml}$ of serous fluid was drained. The following day his clinical condition deteriorated, with tachypnoea, tachycardia, hypotension, and desaturation. A 12 lead ECG showed notably reduced voltages in all leads (panel B) compared to the admission ECG (panel A). The heart could not be visualised on transthoracic echocardiography. The chest $x$ ray (panel C) showed wide separation of the pericardium from the heart. Aspiration of $1000 \mathrm{ml}$ of air from the pericardium resulted in immediate clinical improvement. The pericardial fluid showed neutrophilia consistent with acute pericarditis. Blood and pericardial fluid cultures, Heaf test, and a cardiomyopathy screen were all negative. Antibiotics were stopped and the pericardial drain removed after four days. Further recovery was uneventful.

The presence of air in the pericardium may electrically insulate the heart, and manifest as reduced ECG voltages. Prompt aspiration is required to prevent tamponade.

H Gan

J M Simpson h.gan@doctors.org.uk
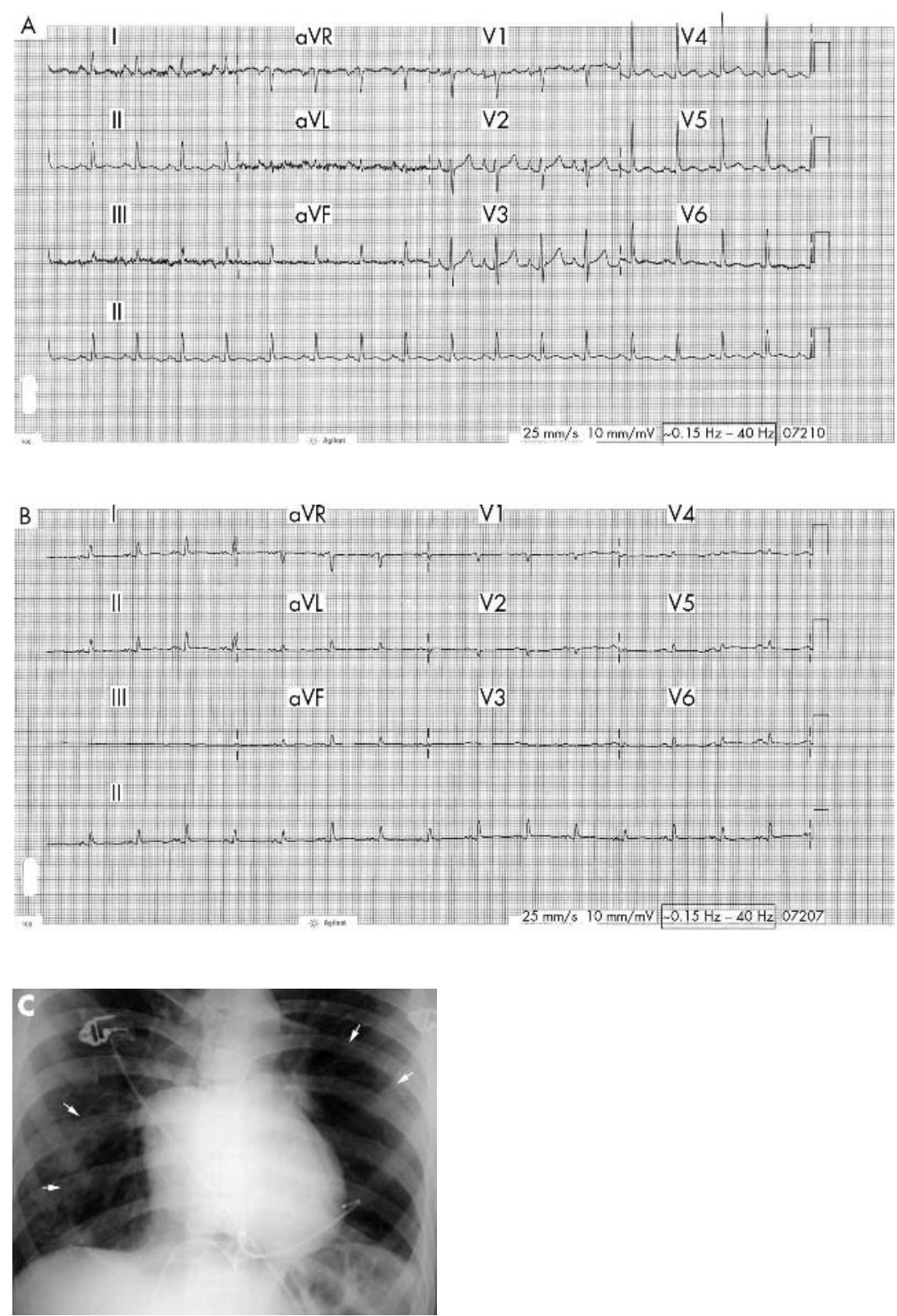